\title{
A RELATIONSHIP BETWEEN READING AND WRITING PERFORMANCE
}

\author{
Yani Adyawardhani \\ English Department, Politeknik Negeri Bandung, Indonesia
}

\begin{abstract}
The present study is investigating the relationship between students' performance in reading and writing after they have learned from the Subjects of Reading 3 and Essay Writing. The result is a positive correlation although it is not a strong one. There may be some variables that are not studied; therefore it needs a further study to look into the relationship.
\end{abstract}

Keywords: reading performance, writing performance, relationship between reading and writing

\section{Introduction}

Writing is an act of expressing ideas which needs utilization and manipulation of language, either in the first language/mother tongue or a second/foreign language. In learning a language, writing is the ultimate skill learned and the most complicated task to do because it needs not only the knowledge of how to write but also the maturity in understanding the substantive concept. Writing in the academic life is not similar to writing for general purposes; it needs more knowledge and skill in developing it. Writing critically as a consequence of an analysis done to the reading is one of important skills that are necessary in order to be successful academically. Therefore, the demands are not only on the use of language, but also on how the ideas and concepts are expressed and how they reflect the writer's understanding of the issue.

Writing in English for many students in Indonesia, especially students learning English in Politeknik Negeri Bandung (Polban), poses a considerable difficulty because English is not their daily communication language yet the success of their academic achievement mostly depends on their ability to write their final project in English. This type of writing will certainly need skills in reading and writing critically. To write the final project successfully, students need to be able to make use both skills that contribute to each other.

Students studying English in Polban have to go through six semesters of studying. They learn reading English in three semesters through the subjects of Reading 1 focusing on using basic reading strategies, Reading 2 focusing on text comprehension, and Reading 3 focusing on application of critical reading skills. At the same time they learn writing in English as well. They learn how to build basic English sentences and punctuation in Writing 1, build different types of paragraph in Writing 2, and in the subject of Essay Writing they learn how to develop an academic essay applying the skills of sentence and paragraph building effectively. These subjects are learned at different semesters, Reading 1 is learned at Semester1, Reading 2 and Writing 1 at semester 2, and Reading 3 and Writing 2 at semester 3; while Essay Writing is learned at semester 4 when the students are supposedly equipped with the skills to write more 
complicated text making use of the skills in gaining background knowledge and transforming it into a new text.

In this context, the students' reading performance is supposedly related to their performance in writing. However, so far it has not been confirmed that there are significant impacts contributing to each other, and that these two language skills are related to each other. The purpose if this study is to find out whether these students' reading performance has a relationship or not to their performance in writing after learning reading and writing for 4 semesters. Consequently, the study tries to answer the question whether there is a relationship between students' performance in reading and their performance in writing English essays.

\section{Literature Review}

Reading and writing has been recognized as two related activities (Langer \& Flihan, 2000), and both activities are seen as two activities that connect to each other. Flower (1990) asserts that the activity of reading to write theoretically causes a strong interaction between these two processes. The reading process is done with a purpose of producing a new text, manipulating information and transforming it into that purpose; while the writing process is complicated by the needs to form an idea at the same time responding to the ideas and purpose of the author of the text. Further, from this connection there is a benefit of enhancing the power of writing as resulted from the breadth and the depth of reading (Alwasilah, 2012).

Studies on reading writing relationship have different emphasizes. Stotsky (1983) reported her correlation and experimental studies on reading and writing. This study reported that there is a strong correlation between reading and writing; it concluded that better readers are better writers and better writers read more than less writers. It also suggested that better readers tend to produce good and mature sentences. Flower (1990 in Flower et al, 1990) carried out an exploratory study on the role of task representation in reading to write. The task representation is what the writer understands about the situation or context that necessitates the writing. From the study some conceptualizations emerge on task representation in the process of reading to write. First, task is constructed by the writer, second, the process of constructing occurs all along the composing process, and third, different strategies are used in constructing text and integrated tasks.

Recent studies show different foci on the relationship between reading and writing. Sangster, Trousdale \& Anderson (2012) carried out a study on assessment of students' writing after they are given a reading text. The study focuses on assessing students' fidelity to the reading in terms of grammatical and tenses aspects. A study on discourse and cognitive perspectives in the relationship between reading and writing is carried out by Parodi (2007). It observes the use of macro-structural, micro-structural, and super-structural levels of comprehending and producing argumentative texts. The results show that there is a connection between reading and writing processes, as they both share a common knowledge based strategy. Another study by Klein \& Kirkpatrick (2010) focuses on the process of how knowledge of a subject topic increases the quality of the writing. It suggests the importance of sufficient background knowledge about the topic to be written. This is supported by McCutchen (2011) who studied the development of novice writer to become skilled writer. It shows how language fluency, possession of topic knowledge and knowledge about text genre 
determined writing proficiency. This shows that the writing process emphasizes the importance of background knowledge on the topic.

\section{Method and data collection}

Under the theory of reading - writing connection, the present study is trying to find out the relationship between performance in reading and performance in writing. It is under the assumption that there is no relationship between these two $\left(\mathrm{H}_{\mathrm{o}}\right)$, and that there is an alternative assumption that there is a relationship $\left(\mathrm{H}_{\mathrm{a}}\right)$. A correlation study is used for this purpose as it fits to measure relationship (Hatch \& Lazaraton, 1991).

\section{Participants}

The participants in this study are 27 fifth semester students of English Department Polban who had learned reading English text in the subject of Reading 3 in Semester 3 and learned writing English texts in the subject of Essay Writing in Semester 4.

\section{Data}

The data used are the marks of these students on Reading 3 and on Essay Writing.The marks were taken from official mark sheets issued at the end of respective semesters. Although these mark sheets are internal documents, for the purpose of this study permission to use the documents has been granted from the Head of English Department. The following table shows the distribution of the marks for the two subjects.

Table 1. Distribution of the Marks on the Subjects of Reading 3 and Essay Writing

\begin{tabular}{|c|c|c|}
\hline No & Reading 3 & Essay Writing \\
\hline 1 & 57 & 48 \\
\hline 2 & 56 & 69 \\
\hline 3 & 61 & 68 \\
\hline 4 & 78 & 77 \\
\hline 5 & 75 & 70 \\
\hline 6 & 56 & 68 \\
\hline 7 & 57 & 65 \\
\hline 8 & 56 & 48 \\
\hline 9 & 61 & 69 \\
\hline 10 & 64 & 70 \\
\hline 11 & 73 & 69 \\
\hline 12 & 57 & 48 \\
\hline 13 & 61 & 49 \\
\hline 14 & 80 & 88 \\
\hline 15 & 57 & 60 \\
\hline 16 & 74 & 71 \\
\hline 17 & 67 & 72 \\
\hline 18 & 58 & 69 \\
\hline 19 & 72 & 69 \\
\hline 20 & 62 & 66 \\
\hline 21 & 58 & 70 \\
\hline 22 & 63 & 76 \\
\hline 23 & 63 & 67 \\
\hline 24 & 59 & 72 \\
\hline 25 & 57 & 71 \\
\hline 26 & 66 & 77 \\
\hline 27 & 57 & 74 \\
\hline
\end{tabular}


These data are then plotted in a scatter diagram (scatter plot) to see an approximation of the relationship. The scatter plot is presented as follows.

\section{Diagram 1 The scatter plot of Reading 3 and Essay Writing}

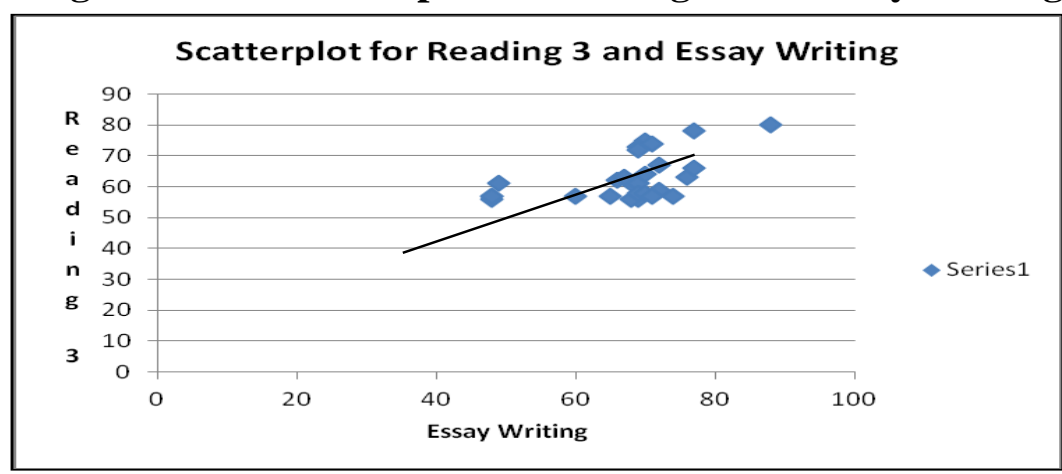

The diagram shows that there is a direct linear relationship. Although the marks are clustered in one area, the whole picture shows that there is a possibility of a relationship between the two subjects. The next step is to calculate the correlation coefficient to justify the strength of the relationship.

\section{The calculation}

To calculate the correlation between these two sets of marks, the data are denoted by $\mathrm{x}$ for the score of Essay Writing and y for Reading 3 and are presented in the following table.

Table 2. The $x$ and $y$ values of the data

\begin{tabular}{|c|c|c|c|c|c|}
\hline & $\mathbf{X}$ & $\mathbf{Y}$ & $\mathbf{X}^{2}$ & $\mathbf{Y}^{2}$ & XY \\
\hline 1 & 48 & 57 & 2304 & 3249 & 2736 \\
\hline 2 & 69 & 56 & 4761 & 3136 & 3864 \\
\hline 3 & 68 & 61 & 4624 & 3721 & 4148 \\
\hline 4 & 77 & 78 & 5929 & 6084 & 6006 \\
\hline 5 & 70 & 75 & 4900 & 5625 & 5250 \\
\hline 6 & 68 & 56 & 4624 & 3136 & 3808 \\
\hline 7 & 65 & 57 & 4225 & 3249 & 3705 \\
\hline 8 & 48 & 56 & 2304 & 3136 & 2688 \\
\hline 9 & 69 & 61 & 4761 & 3721 & 4209 \\
\hline 10 & 70 & 64 & 4900 & 4096 & 4480 \\
\hline 11 & 69 & 73 & 4761 & 5329 & 5037 \\
\hline 12 & 48 & 57 & 2304 & 3249 & 2736 \\
\hline 13 & 49 & 61 & 2401 & 3721 & 2989 \\
\hline 14 & 88 & 80 & 7744 & 6400 & 7040 \\
\hline 15 & 60 & 57 & 3600 & 3249 & 3420 \\
\hline 16 & 71 & 74 & 5041 & 5476 & 5254 \\
\hline 17 & 72 & 67 & 5184 & 4489 & 4824 \\
\hline 18 & 69 & 58 & 4761 & 3364 & 4002 \\
\hline 19 & 69 & 72 & 4761 & 5184 & 4968 \\
\hline 20 & 66 & 62 & 4356 & 3844 & 4092 \\
\hline 21 & 70 & 58 & 4900 & 3364 & 4060 \\
\hline 22 & 76 & 63 & 5776 & 3969 & 4788 \\
\hline 23 & 67 & 63 & 4489 & 3969 & 4221 \\
\hline 24 & 72 & 59 & 5184 & 3481 & 4248 \\
\hline 25 & 71 & 57 & 5041 & 3249 & 4047 \\
\hline 26 & 77 & 66 & 5929 & 4356 & 5082 \\
\hline 27 & 74 & 57 & 5476 & 3249 & 4218 \\
\hline$\sum$ & 1820 & 1705 & 125040 & 109095 & 115920 \\
\hline
\end{tabular}


The formula used in the calculation of correlation coefficient is the Pearson Productmoment (Hatch \& Lazaraton, 1991:434) represented by the symbol $r$. The subscript $\mathrm{x}$ and $\mathrm{y}$ are attached to it to show that the correlation is between variables $\mathrm{x}$ and $\mathrm{y}$. the symbol the becomes $r_{x y}$. The calculation using the formula is as follows:

$$
\begin{aligned}
& \mathrm{N}\left(\sum \mathrm{XY}\right)-\left(\sum \mathrm{X}\right)\left(\sum \mathrm{Y}\right) \\
& r_{x y}=\frac{\mathrm{N}}{\sqrt{\left[\mathrm{N}\left(\sum \mathrm{X}^{2}\right)-\left(\sum \mathrm{X}\right)^{2}\right]\left[\mathrm{N}\left(\sum \mathrm{Y}^{2}\right)-\left(\sum \mathrm{Y}\right)^{2}\right]}} \\
& =\underline{27(115920)-(1820)(1705)} \\
& \sqrt{\left[27(125040)-(1820)^{2}\right]\left[27(109095)-(1705)^{2}\right.} \\
& =\underline{3129840-3103100} \\
& \sqrt{(3376080-3312400)-(2945565-2907025)} \\
& =\frac{26740}{\sqrt{(63680)(38540)}} \\
& =\frac{26740}{\sqrt{2454227200}} \\
& =\frac{26740}{49540.1574} \\
& =0.5397 \Longrightarrow 0.54
\end{aligned}
$$

To check on the data that both sets of variables co-vary, the covariance should be calculated using the formula:

$$
\operatorname{Cov}_{\mathrm{xy}}=\frac{\sum(\mathrm{X}-\mathrm{X})(\mathrm{Y}-\mathrm{Y})}{\mathrm{N}-1}
$$

In order to be able to calculate covariance we need to calculate the standard deviation (SD) and mean $(\mathrm{X}, \mathrm{Y})$ or $\mathrm{M}$. Table 2 needs to be expanded in order that the data for the calculation of $\left(\mathrm{X}-\mathrm{M}_{\mathrm{x}}\right)$ and $\left(\mathrm{Y}-\mathrm{M}_{\mathrm{y}}\right)$ is clearly presented. 
Table 3 The data for covariance and standard deviation calculation

\begin{tabular}{|c|c|c|c|c|c|c|c|c|}
\hline & X & Y & $X^{2}$ & $\mathrm{Y}^{2}$ & XY & X-Mx & Y-My & $\begin{array}{c}(\mathrm{X}-\mathrm{Mx})(\mathrm{Y}- \\
\mathrm{My})\end{array}$ \\
\hline 1 & 48 & 57 & 2304 & 3249 & 2736 & $-18,714$ & $-5,929$ & 110,949 \\
\hline 2 & 69 & 56 & 4761 & 3136 & 3864 & 2,2857 & $-6,929$ & $-15,83673$ \\
\hline 3 & 68 & 61 & 4624 & 3721 & 4148 & 1,2857 & $-1,929$ & $-2,479592$ \\
\hline 4 & 77 & 78 & 5929 & 6084 & 6006 & 10,286 & 15,07 & 155,0204 \\
\hline 5 & 70 & 75 & 4900 & 5625 & 5250 & 3,2857 & 12,07 & 39,66327 \\
\hline 6 & 68 & 56 & 4624 & 3136 & 3808 & 1,2857 & $-6,929$ & $-8,908163$ \\
\hline 7 & 65 & 57 & 4225 & 3249 & 3705 & $-1,7143$ & $-5,929$ & 10,16327 \\
\hline 8 & 48 & 56 & 2304 & 3136 & 2688 & $-18,714$ & $-6,929$ & 129,6633 \\
\hline 9 & 69 & 61 & 4761 & 3721 & 4209 & 2,2857 & $-1,929$ & $-4,408163$ \\
\hline 10 & 70 & 64 & 4900 & 4096 & 4480 & 3,2857 & 1,071 & 3,520408 \\
\hline 11 & 69 & 73 & 4761 & 5329 & 5037 & 2,2857 & 10,07 & 23,02041 \\
\hline 12 & 48 & 57 & 2304 & 3249 & 2736 & $-18,714$ & $-5,929$ & 110,949 \\
\hline 13 & 49 & 61 & 2401 & 3721 & 2989 & $-17,714$ & $-1,929$ & 34,16327 \\
\hline 14 & 88 & 80 & 7744 & 6400 & 7040 & 21,286 & 17,07 & 363,3776 \\
\hline 15 & 60 & 57 & 3600 & 3249 & 3420 & $-6,7143$ & $-5,929$ & 39,80612 \\
\hline 16 & 71 & 74 & 5041 & 5476 & 5254 & 4,2857 & 11,07 & 47,44898 \\
\hline 17 & 72 & 67 & 5184 & 4489 & 4824 & 5,2857 & 4,071 & 21,52041 \\
\hline 18 & 69 & 58 & 4761 & 3364 & 4002 & 2,2857 & $-4,929$ & $-11,26531$ \\
\hline 19 & 69 & 72 & 4761 & 5184 & 4968 & 2,2857 & 9,071 & 20,73469 \\
\hline 20 & 66 & 62 & 4356 & 3844 & 4092 & $-0,7143$ & $-0,929$ & 0,663265 \\
\hline 21 & 70 & 58 & 4900 & 3364 & 4060 & 3,2857 & $-4,929$ & $-16,19388$ \\
\hline 22 & 76 & 63 & 5776 & 3969 & 4788 & 9,2857 & 0,071 & 0,663265 \\
\hline 23 & 67 & 63 & 4489 & 3969 & 4221 & 0,2857 & 0,071 & 0,020408 \\
\hline 24 & 72 & 59 & 5184 & 3481 & 4248 & 5,2857 & $-3,929$ & $-20,76531$ \\
\hline 25 & 71 & 57 & 5041 & 3249 & 4047 & 4,2857 & $-5,929$ & $-25,40816$ \\
\hline 26 & 77 & 66 & 5929 & 4356 & 5082 & 10,286 & 3,071 & 31,59184 \\
\hline 27 & 74 & 57 & 5476 & 3249 & 4218 & 7,2857 & $-5,929$ & $-43,19388$ \\
\hline$\sum$ & 1820 & 1705 & 125040 & 109095 & 115920 & 18,714 & 5,929 & 994,4796 \\
\hline
\end{tabular}

The calculation of standard deviations and the means (averages) are as follows:

$\sum \mathrm{X}$

$\mathrm{M}_{\mathrm{x}}=\mathrm{N}-1$

$=182 \frac{0}{26}=66.714$

$\sum \mathrm{Y}$

$\mathrm{M}_{\mathrm{y}}=\mathrm{N}-1$

$=170 \frac{5}{26}=62.929$ 
The standard deviations are as follows:

$$
\begin{aligned}
\operatorname{SD~}\left(\mathrm{S}_{\mathrm{x}}\right) & =\sqrt{\frac{\sum \mathrm{X}^{2}-\left(\sum \mathrm{X}\right)\left(\sum \mathrm{X}\right) / \mathrm{N}}{\mathrm{N}-1}} \\
& =\sqrt{\frac{125040-((1820)(1820)) / 27}{26}} \\
& =\sqrt{\frac{125040-122681.48}{26}}=\frac{\sqrt{2358.52}}{26}=\sqrt{ } 90.71=9.524 \\
\mathrm{SD}\left(\mathrm{S}_{\mathrm{y}}\right) & =\sqrt{\frac{\mathrm{N}-1}{26}}=\sqrt{\frac{109095-((1705)(1705)) / 27}{26}}=\sqrt{1427.41}=\sqrt{ } 54.900=7.409
\end{aligned}
$$

The calculation of the covariance:

$$
\begin{aligned}
\operatorname{cov}_{\mathrm{xy}}= & \frac{\sum(\mathrm{X}-\mathrm{X}) \overline{(\mathrm{Y}-\mathrm{Y})}}{\mathrm{N}-1} \\
= & \frac{994,4796}{26}=38.249
\end{aligned}
$$

This value shows how much the two sets co-vary, and it must be adjusted by dividing it with the standard deviation of both variables. The result is the adjusted or standardized covariance and is also the correlation coefficient. The calculation is as follows:

$r_{x y}=\frac{\operatorname{Cov}_{\mathrm{xy}}}{\mathrm{S}_{\mathrm{x}} \mathrm{S}_{\mathrm{y}}}=\frac{38.249}{(9.524) \overline{(7.409)}}=\frac{38.249}{70.563}=0.5420 \Rightarrow 0.54$

The calculation of coefficient correlation by taking into consideration the variance between the two sets of variables yields the same result as that of using the formula of Pearson product moment.

\section{Result and Discussion}

The calculation for the coefficient correlation of the relationship between students' reading and writing is resulted in a coefficient of 0.54 . With the degree of freedom of $25(27-2)$ the critical 
value for Pearson product-moment correlation is 0.3809 ; the calculated value of 0.54 is higher than the critical value. This means that the null hypotheses $\left(\mathrm{H}_{\mathrm{o}}\right)$ that there is no relationship between the performance of reading and writing are rejected; and the alternative hypotheses $\left(\mathrm{H}_{\mathrm{a}}\right)$ are accepted.

Although the coefficient correlation shows that there is a relationship between the two variables, the strength of the association (Hatch \& Lazaraton, 1991:440) needs to be determined to see how well they share the variance or "...the variability of score around the mean." To get an overlap, the $r$ value is squared, then for 0.54 we get 0,2916 or about $30 \%$ overlap.

With this result the answer to the question whether there is a relationship between students' performance in reading and their performance in writing English essays can be answered positively that there is a relationship. However, the connection is not too strong as only 8 students whose performances in reading correlates with that of writing out of 27 students.

The present study, in some way, supports findings in Stotsky's study (1983) that there is a connection between reading and writing even though it is not as strong. It seems that in this study there must be some variables that are not accounted for and that for this group of students there may be some aspects that are different in Reading 3 and in Essay Writing. The skill in critical reading is only helpful for some students. Therefore, some explanation is necessary in this condition.

First, the process of teaching and learning of Reading 3 for most students may not contribute to the process of writing an essay. For this condition, there are some variables that may contribute to the fact, such as teacher's teaching strategy, teaching materials, and reading and writing tasks. As a study by Flower (1990 in Flower et al, 1990) shows that the process of reading to write may be determined by the task representation that the writer understands prior to and while writing. The other reason relates to the mastery of vocabulary and grammar both in writing and reading. A study by Sangster, Trousdale \& Anderson (2012) emphasizes on fidelity of grammar and tenses in writing after the reading process; therefore grammar and possibly tenses are significant contributor to the good performance in writing. A warning, however, is given by Stotsky (1983) that relying too much on grammar and writing practice does not contribute to better writing compared with the provision of reading practice.

Another possible explanation is the lack of provision of experience for the students to get background knowledge in the reading sessions which is important in the development of ideas in writing. Klein \& Kirkpatrick (2010) and McCutchen (2011) study the importance of background knowledge in producing quality writing, the knowledge about the topic that could be transformed into a new text. Similarly, writing needs the use of knowledge-based strategy (Parodi, 2007). It is obvious that both in reading and writing background knowledge is important.

From the empirical study, we learn that there is a positive relationship between reading and writing performances. However, the fact shows that less number of students may have benefited from the reading class which they use to support their writing performances. We can also learn another kind of relationship which is a direct one between reading and writing. Hatch and Lazaraton (1991) assert that a correlation measure can give answers to questions whether students who score well on an exam also do well on the other, and those who are weak in the 
exam also perform poorly on the other. In this case, weak performance in reading for most students in the study contributes to their weak performance in writing. Similarly, those who are good in reading perform well in writing.

This study may not give all the answer to the relationship issues between reading and writing. However, it may shed some light on the reading and writing performance for this particular students, which is important in understanding the teaching and learning process of both subjects. The result of this study, then, warrants a further study taking into account aspects of reading that affect writing such as grammar and vocabulary mastery, and other aspects that contribute to the reading and writing process.

\section{Conclusion}

In conclusion, the present study shows that there is a positive relationship between students' performances in reading and in writing. The relationship, however, is not a strong one. There may be some variables in both subjects that are not measured in this study, such as the teaching strategies, the tasks that students have to perform, grammar and vocabulary mastery, and provision of experience in getting background knowledge that is necessary in writing. The study is worth replicating, approaching the same subjects from different methods to address the previous variables not yet taken into account.

\section{References}

- Alwasilah, A.C. (2012). Powerful Readers Versus the Helpless Readers. The Jakarta Post, 14 January 2012

- Flower, L. (1990).The Role of Task Representation in Reading-to-Write, in Flower, L.; Stein, V.; Ackerman, J.; Kantz, M.J.; McCormick, K. and Peck, W.C. (1990). Reading to Write. Exploring a Cognitive \& Social Process. New York: Oxford University Press.

- Hatch, E. \& Lazaraton, A. (1991). The Research Manual. Design and Statistics for Applied Linguistics. New York: Newbury House Publishers

- Klein, P.D. \& Kirkpatrick, L.C. (2010). A Framework for Content Area Writing: Mediators and Moderators. Journal of Writing Research, 2 (1), 1 - 46

- Langer, J.A. and Flihan, S. (2000). Writing and Reading Relationship: Constructive Tasks. Available at http://www.albany.edu/cela/publication/article/writeread.htm. Accessed on 27 Nov 2012.

- McCutchen, D. (2011). From Novice to Expert: Implications Of Language Skills And Writing-Relevant Knowledge For Memory During The Development Of Writing Skill. Journal of Writing Research, 3 (1), 51 - 68

- Parodi, G. (2007). Reading - Writing Connections: Discourse Oriented Research. Reading and Writing (2007) 20:225-250

- Sangster, P., Trousdale, G. \& Anderson, C. (2012). From Reading to Writing: Evaluating the Writer'S Craft as a Means of Assessing Schools Student Writing. Journal of Writing Research, 4 (1), 1 - 30

- Stotsky, S. (1983). Research on Reading/Writing Relationships: A Synthesis and Suggested Direction. Language Arts, 60 (5), 627-642 